\title{
Degradation of extracellular matrix regulates osteoblast migration: a microfluidic-based study
}

\author{
N. Movilla, C. Borau, C. Valero and J.M. García-Aznar \\ Multiscale in Mechanical and Biological Engineering, Aragon Institute of Engineering Research, Department of \\ Mechanical Engineering, University of Zaragoza, 50018 Zaragoza, Spain.
}

\begin{abstract}
Bone regeneration is strongly dependent on the capacity of cells to move in a 3D microenvironment, where a large cascade of signals is activated. To improve the understanding of this complex process and to advance in the knowledge of the role of each specific signal, it is fundamental to analyze the impact of each factor independently. Microfluidic-based cell culture is an appropriate technology to achieve this objective, because it allows recreating realistic 3D local microenvironments by taking into account the extracellular matrix, cells and chemical gradients in an independent or combined scenario. The main aim of this work is to analyze the impact of extracellular matrix properties and growth factor gradients on 3D osteoblast movement, as well as the role of cell matrix degradation. For that, we used collagenbased hydrogels, with and without crosslinkers, under different chemical gradients, and eventually inhibiting metalloproteinases to tweak matrix degradation. We found that osteoblast's 3D migratory patterns were affected by the hydrogel properties and the PDGF-BB gradient, although the strongest regulatory factor was determined by the ability of cells to remodel the matrix.
\end{abstract}

Keywords: osteoblasts, chemotaxis, crosslinking, collagen, marimastat, mechanical properties.

\section{Introduction}

Cell migration plays a critical and crucial function on many regenerative processes, including bone regeneration. Migration of highly motile cells (such as fibroblasts) has been the focus of intensive experiments and mathematical modeling research (Petrie et al, 2012; Moreno-Arotzena et al, 2014, 2015; Ribeiro et al, 2016; Valero et al, 2015; Koppenol et al, 2016), specifically in wound healing applications. However, there are few experimental works in the literature regarding osteoblast migration (Ishaug et al, 1996; Dee et al, 1999; Hengartner et al, 2013), in comparison with the more numerous mathematical modeling approaches due to the wide variety of modeling techniques (Giorgi et al, 2016; Ribeiro et al, 2015; Byrne et al, 2011; Borau et al, 2011; GomezBenito et al, 2005).

This is the post-print version of the following article: Movilla, N., Borau, C., Valero, C., \& García-Aznar, J. M. (2018). Degradation of extracellular matrix regulates osteoblast migration: A microfluidic-based study. Bone, 107, 10-17. doi: 10.1016/j.bone.2017.10.025, which has been published in final form here. 
Most of in-vitro experiments of osteoblast migration have been developed with cells of different animal origin, for instance neonatal rat calvarial osteoblasts (Dee et al, 1999) or murine osteoblastic cell lines (Uchihashi et al, 2013; Ehrbar et al, 2011). However there are not many in-vitro works of 3D migration with human osteoblasts. In fact, as far as authors are concerned, the most relevant work corresponds to the one from (Robin et al, 2016) that studied 3D migration induced by apatite.

Osteoblast population migratory response to chemo-attractants has been normally studied on chosen substrates or non-porous surfaces (for example, metals used for orthopedic/dental applications) (Dee et al, 1999) or using commercially available Boyden chamber assays (Hengartner et al, 2013). However, none of these assays allow examination of cellular chemotaxis on 3D environments. The present study adapts the well-documented tumor cell migration assays under a chemical gradient (Boussommier-Calleja et al, 2016; Bersini et al, 2014) to examine osteoblast 3D migration.

To recreate physiological osteoblast 3D migration, the use of biomimetic hydrogels is fundamental. Osteoblast culture using type I collagen gel, which is the major component of bone matrix, was first described by Elsdale and Bard (1972). Osteoblasts in such culturing conditions maintained their function, 3D structure and cell-cell interaction (Uchihashi et al, 2013). In fact, they found that osteoblasts migrated into the gel, extended dendritic protrusions towards neighboring cells, and synthesized collagen fibrils, mineralizing around themselves. Nevertheless, Uchihashi et al, (2013) focused their work on understanding the transition mechanism from osteoblast to osteocyte, but did not quantify osteoblast migration. Mullen et al (2015) investigated the effect of collagen cross-linking (with glutaraldehyde) in conjunction with substrate thickness on the 2D osteogenic cell behaviour finding that MC3T3 cells cultured on a soft fibrous substrate attain the same spread cell area as those cultured on a much higher modulus, but nonfibrous substrate. More recently, Robin et al, (2016) showed that osteoblast 3D invasion is enhanced by the presence of apatite bone mineral in the extracellular matrix (ECM), although migration was not quantified in terms of speed and directionality. To date, to the best of authors' knowledge, the migration characteristics of osteoblasts on 3D collagen gels modified with cross-linkers have not been examined.

Different kind of growth factors have been studied in the literature to evaluate the osteoblast chemotactic properties: TGF- $\beta$ is a chemoattractant used for stimulating rat osteosarcoma cells (Lucas, 1989) and human osteoblasts (Lind et al, 1995); OP-1 is chemically and structurally similar to bone morphogenetic protein-2, a chemoattractant for human osteoblasts (Lind et al, 1995); insulin-like growth factors (IGF-1 and IGF-2) also stimulate the site-directed migration of osteoblasts (Lind et al, 
1995; Nakasaki et al, 2008); Robin et al (2016) demonstrated that the presence of bone apatite promotes osteoblast migration, possibly through ion release and/or mediated by the roughness of the apatite or the alteration of the mechanical properties. In any case, the platelet derived growth factor $\beta$ (PDGF-BB) has been found to be one of the most potent chemotactic factors for primary osteoblasts and osteoblastic cell lines in 2D cell migration (Casati et al, 2014; Hengartner et al, 2013; Mehrotra et al, 2004; Lind et al, 1995). In fact, PDGF has been used as a treatment for improving bone fracture healing in preclinical and clinical stages (Hollinger et al, 2008; DiGiovanni et al, 2013).

To migrate in 3D, cells can use either proteolytic (mesenchymal) or non-proteolytic (amoeboid) strategies (Doyle et al, 2013). In proteolytic migration, cells adhere to matrix secreting active metalloproteases (MMP), which break down the ECM and thus create macroscopic holes that allow their movement. However, in non-proteolytic migration, cells deform the ECM or squeeze through it, without degradation. From the literature, it is not clear whether osteoblast migration in collagen-based matrices presents a proteolytic or a non-proteolytic strategy. Therefore, the main aim of the present study is to quantitatively examine the migration characteristics of human osteoblasts on 3D collagen-based matrices. For that, we used $4 \mathrm{mg} / \mathrm{ml}$ collagen hydrogels, eventually adding crosslinkers and/or inhibiting metalloproteases activity. In addition, different PDGF-BB chemical gradients were induced in order to understand their regulatory role.

\section{Materials and Methods}

\subsection{Fabrication of microfluidic chips}

Microdevices were fabricated in PDMS following the methodology described by Shin et al, (2012). Actually, they were made of polydimethylsiloxane (PDMS-Dow Corning GMbH Sylgard 184, Dow Chemical, Germany) at a 10:1 ratio of base to curing agent. PDMS microdevices were plasma-bonded to $35 \mathrm{~mm}$ glass-bottom petri dishes (IBIDI) and treated with poly-D-lysine (PDL) solution (Sigma- Aldrich, Germany) at $1 \mathrm{mg} / \mathrm{ml}$ for enhanced surface-matrix attachment.

The geometry of the microfluidic devices (Fig. 1A, B) consists of two media channels running parallel to and located on either side of an extended central channel containing the hydrogel with the cells, which simulates the bone matrix (based on the one used by Farahat et al, 2012).

This is the post-print version of the following article: Movilla, N., Borau, C., Valero, C., \& García-Aznar, J. M. (2018). Degradation of extracellular matrix regulates osteoblast migration: A microfluidic-based study. Bone, 107, 10-17. doi: 10.1016/j.bone.2017.10.025, which has been published in final form here. 

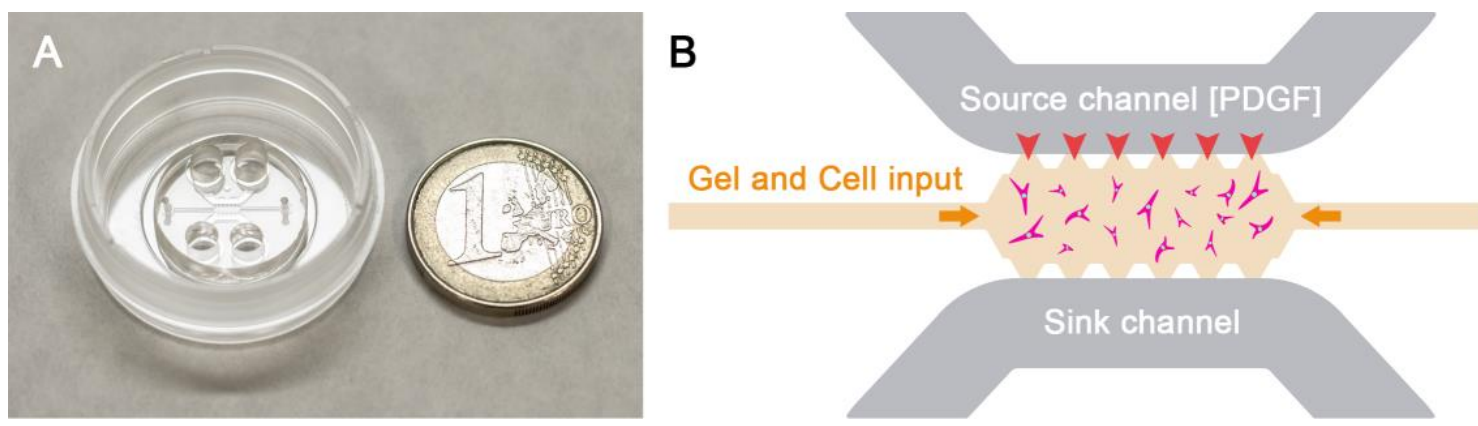

Fig.1. A) Picture of the microfluidic device placed inside a $35 \mathrm{~mm}$ plate. B) Scheme of the central part of the device. The central channel is filled with collagen and cells through the auxiliary channels (orange horizontal arrows). The two main media channels, namely the source channel and the sink channel, ensure the hydration and diffusion of the PDGF-BB through the hydrogel. Red arrow heads indicate the direction of the chemical gradient. Importantly, the height of the channels is $300 \mu \mathrm{m}$ for all the geometry. Further geometric details can be found at Moreno-Arotzena et al, 2015.

\subsection{Collagen-based gels and 3D cell culture}

The hydrogel used to simulate bone matrix was collagen type I (BD Biosciences), which was prepared to a final concentration of $4 \mathrm{mg} / \mathrm{ml}$ with DPBS (Lonza) following the methodology proposed by Shin et al, (2012). The dilution was brought to $\mathrm{pH} 7.4$ with $0.5 \mathrm{M} \mathrm{NaOH}$. Cells suspended in culture medium were mixed with the collagen hydrogel to a final dilution of $1 \times 10^{5} \mathrm{cells} / \mathrm{ml}$. This dilution was then pipetted into the central gel chamber and the hydrogel was confined by surface tension. Once in place, collagen gel solution was polymerized in a humidity chamber at $37 \circ \mathrm{C}$ and $5 \% \mathrm{CO}_{2}$ for 20 minutes. After that, the matrix was hydrated with Osteoblast Growth Medium (OGM) and incubated overnight for stabilization of matrix and cell adhesion.

Human Osteoblast (HOB, C-12720, Promocell) cells were cultured using Osteoblast Growth Medium (C-27001, $0.1 \mathrm{ml} / \mathrm{ml}$ of Fetal Calf Serum, Promocell) and used in passages 3-6. Cells were maintained in a humidified atmosphere incubator at $37{ }^{\circ} \mathrm{C}$ and with $5 \% \mathrm{CO}_{2}$.

\subsection{Mechanical and microstructural characterization of collagen-based scaffolds}

Collagen hydrogels used for cell culture were characterized by rheology to obtain their mechanical properties using a Haake Rheostress 1 rheometer. Collagen hydrogels were immediately pipetted on the rheometer after being prepared and polymerized in-situ during 24 hours at $37^{\circ} \mathrm{C}$. All samples were tested using a cone-plate configuration with a $35 \mathrm{~mm}$ diameter and a cone angle of 1 o. To avoid dehydration the samples were sealed with low viscosity oil. After 24 hours the gels were mechanically loaded applying oscillatory strain sweeps with an excitation frequency of $0.1 \mathrm{~Hz}$. 
In addition, microarchitecture of the hydrogels was evaluated by means of scanning electron microscopy (SEM). Images were acquired using a SEM Inspect ${ }^{\mathrm{TM}}$ F50 (FEI Company, Eindhoven, The Netherlands) in an energy range between 0-30 keV. The hydrogels for the microstructural study were prepared as described before and allowed to stabilize for 24 hours in a humidified chamber at $37^{\circ} \mathrm{C}$. The preparation of the samples was made by firstly frozen each sample separately in liquid nitrogen. Subsequently, the tubes containing the samples were submitted to lyophilizer (Telstar cryodos Freeze Dryer) for at least $24 \mathrm{~h}$. Finally, the samples were coated with a carbon film before they were examined with the SEM technique.

To modify the mechanical properties of the collagen-based hydrogels we altered the microstructure via crosslinking with Transglutaminase (TG2) (Fraley et al, 2015), which increases strength and resistance of biopolymers to proteolytic digestion (Chau et al, 2005; Jones et al, 2006). Purified recombinant human Transglutaminase II (TG2) in solution (R\&D Systems) at $25 \mu \mathrm{g} / \mathrm{ml}$ was mixed into the hydrogel solution and softly pipetted into the devices. The enzyme was added in the last place to the collagenreaction mix to minimize any self-imposed crosslinking. The hydrogel was polymerized for $20 \mathrm{~min}$ in a humidified chamber, at $37{ }^{\circ} \mathrm{C}$ and $5 \% \mathrm{CO}_{2}$. Following polymerization, the matrix was hydrated an incubated overnight in the same conditions.

\subsection{Application of a chemical gradient}

In order to recreate the local conditions that occur in the environment of a bone fracture or injury, we induce in the microfluidic device a chemical gradient using PDGF$\mathrm{BB}$ as chemoattractant. The concentrations of the recombinant human PDGF-BB (Invitrogen) isoform used in the experiments for the application of the chemical gradient with human osteoblasts were $5 \mathrm{ng} / \mathrm{ml}$ and $50 \mathrm{ng} / \mathrm{ml}$ respectively.

After $24 \mathrm{~h}$ of incubation, PDGF-BB (Abcam) was added achieving a gradient across the gel by adding the growth factor $(5 \mathrm{ng} / \mathrm{ml}$ or $50 \mathrm{ng} / \mathrm{ml})$ containing culture medium to only one channel, while new medium alone was added to the other channel. The chemical gradient was established by a diffusive process across the hydrogel (MorenoArotzena et al, 2014; Moreno-Arotzena et al, 2015; Del Amo et al, 2016).

\subsection{Inhibition of matrix degradation}

To advance in the understanding of the MMP activity, we performed migration experiments in the presence of the broad-range MMP-inhibitor Marimastat which binds zinc atoms into the active site of metalloproteinases disabling the enzymes and blocking their function (Scott et al, 1998). Proteolytic activity was inhibited using the inhibitor Marimastat (Sigma) or vehicle control DMSO (Amresco). It was mixed into the collagen gel solution and polymerized in a humidity chamber at 37을 $\mathrm{C}$ and $5 \% \mathrm{CO} 2$ for This is the post-print version of the following article: Movilla, N., Borau, C., Valero, C., \& García-Aznar, J. M. (2018). Degradation of extracellular matrix regulates osteoblast migration: A microfluidic-based study. Bone, 107, 10-17. doi: 10.1016/j.bone.2017.10.025, which has been published in final form here. 
20 minutes. After that, the matrix was hydrated with OGM medium to achieve a final concentration of $10 \mu \mathrm{M}$.

\subsection{Quantification of osteoblast migration}

Time-lapse imaging was carried out with a Nikon D-Eclipse Ti Microscope with a $10 \mathrm{X}$ objective, acquiring phase contrast images every $20 \mathrm{~min}$ for $24 \mathrm{~h}$. The focal plane was chosen to be in the middle along the z-axis of the device ensuring that the tracked cells were embedded within the 3D network. During the experiment, the incubation conditions were controlled and held at $37 \stackrel{\circ}{\circ}, 5 \% \mathrm{CO}_{2}$ and $95 \%$ of humidity. Cell tracking was performed using a hand coded semi-automatic MATLAB script. Acquired data was then analyzed in terms of mean and effective speeds, minimum square displacements, directional ratio and velocity orientation. Additionally, cell trajectories were fitted to both a persistent random walk model (PRW) and an anisotropic persistent random walk model (APRW) following the methods described in (Pei-Hsun et al, 2015; Roman Gorelik et al, 2014), obtaining adjusted parameters of persistence time, persistence speed and diffusion coefficient. The significance of the observed differences between controls and other explored conditions was obtained via Kruskalwallis and Anova tests.

\subsection{Quantification of fiber alignment}

Fiber alignment of collagen networks was obtained by analyzing their SEM images (up to ten for each sample) at different zoom levels. The alignment index $(\alpha)$ was estimated using a discrete Fourier Transform ( $F T$ ) method, following that described in Sander et al, 2009 and Fraley et al,2015. Broadly, FT allows the description of a digital image (size $M \times N)$ in terms of the frequency of its components and can be calculated as:

$$
F T(u, v)=\sum_{x=0}^{M-1} \sum_{y=0}^{N-1} f(x, y) e^{-i 2 \pi(u x / M+u y / N)}
$$

where $x$ and $y$ are the spatial coordinates of the image, $u$ and $v$ the frequency components along $x$ and $y$ in the Fourier domain, and $i=\sqrt{-1}$. The magnitude of the $F T$ is expressed as:

$|F T(u, v)|^{2}=R^{2}(u, v)+I^{2}(u, v)$

where $R$ and $I$ are the real and imaginary parts of FT respectively. Then, the integrated intensity $\left(F_{I}(\theta)\right)$ can be calculated through the image center at different orientations, in polar coordinates, to finally transform it to Cartesian coordinates and obtain: 
$C_{x y}(\theta)=\left[F_{I}(\theta) \cos (\theta), F_{I}(\theta) \sin (\theta)\right]$

which is used, together with its transpose $\left(\left[C_{x y}{ }^{T} C_{x y}\right]\right)$, to extract the eigenvalues

$\left(\lambda_{2}>\lambda_{1}\right)$ that determine the alignment index, that ranges from 0 (completely isotropic structures) to 1 (completely aligned structures):

$\alpha=1-\lambda_{2} / \lambda_{1}$

\section{Results}

To understand human osteoblast 3D migration, we studied them under different conditions, either by using chemical gradients, crosslinked hydrogels or metalloprotease inhibitors. We tracked the trajectories of about 130 cells per condition, and extracted several migration parameters such as speeds, minimum square displacements (MSD) or directionality ratio. Then, the MSD curves were fitted to both a typical persistent random walk model (PRW) and an anisotropic persistent random model (APRW) (Pei-Hsun Wu et al, 2015) that projected the trajectories into a primary and a secondary direction to analyze their inherent anisotropy. Hence, we obtained the anisotropy index and the diffusion coefficient in the primary and secondary directions (Figure S2 an S3).

\subsection{Microstructural study and mechanical response of hydrogels}

Structural information regarding collagen fibrils has been collected using electron microscopy techniques. Our analyses show the structural information of collagen hydrogels at concentrations of $4 \mathrm{mg} / \mathrm{ml}$. We also altered the microstructure by crosslinking $4 \mathrm{mg} / \mathrm{ml}$ collagen hydrogels with $25 \mu \mathrm{g} / \mathrm{ml}$ Transglutaminase (TG2) which increases strength and resistance of biopolymers to proteolytic digestion (Chay et al, 2005; Jones et al, 2006). We observed a different gel polymerization and reorganization of fiber alignment and obtained collagen hydrogels with increased strength and resistance to deformation (see Table 1).

The mechanical properties of the hydrogels used for cell culture were studied within their linear elastic region. Rheological analysis showed a higher stiffness in hydrogels with higher collagen concentration when small deformations were applied $(\gamma<10 \%)$. We did not observe significant differences in the stiffness of $4 \mathrm{mg} / \mathrm{ml}$ gels when we added the crosslinking enzyme.

\begin{tabular}{lllll}
\hline $\begin{array}{l}\text { Hydrogel } \\
\text { composition }\end{array}$ & $\begin{array}{l}\text { Storage shear } \\
\text { modulus } \mathrm{G}^{\prime} \\
(\mathrm{Pa})\end{array}$ & $\begin{array}{l}\text { Maximum } \\
\text { shear strain }\end{array}$ & $\begin{array}{l}\text { Maximum } \mathrm{G}^{\prime} \\
(\mathrm{Pa})\end{array}$ & $\begin{array}{l}\text { Strain at } \\
\text { maximum } \mathrm{G}^{\prime}\end{array}$ \\
\hline $4 \mathrm{mg} / \mathrm{ml}$ & $121.03 \pm 9.94$ & 0.403 & 191.2 & 0.403 \\
\hline
\end{tabular}

This is the post-print version of the following article: Movilla, N., Borau, C., Valero, C., \& García-Aznar, J. M. (2018). Degradation of extracellular matrix regulates osteoblast migration: A microfluidic-based study. Bone, 107, 10-17. doi: 10.1016/j.bone.2017.10.025, which has been published in final form here. 


\begin{tabular}{lllll}
\hline $4 \mathrm{mg} / \mathrm{ml}+25$ & $127.90 \pm 14.43$ & 0.449 & 285.5 & 0.384 \\
$\mu \mathrm{g} / \mathrm{ml} \mathrm{TG2}$ & & & \\
\hline
\end{tabular}

Table 1. Mechanical properties of the collagen hydrogels used for the in-vitro experiments. Three samples were analyzed for the cases without TG2 and $25 \mu \mathrm{g} / \mathrm{ml}$ of TG2.

Figure 2 shows the architecture of $4 \mathrm{mg} / \mathrm{ml}$ hydrogels at different magnifications $(6.000$ $\mathrm{X}$ and $50.000 \mathrm{X}$ ). The addition of TG2 as crosslinker did not induce strong alterations on the architecture, but seems to increase the number of thin membranes between fibers and overall form a more highly aligned architecture (Figure 2B).
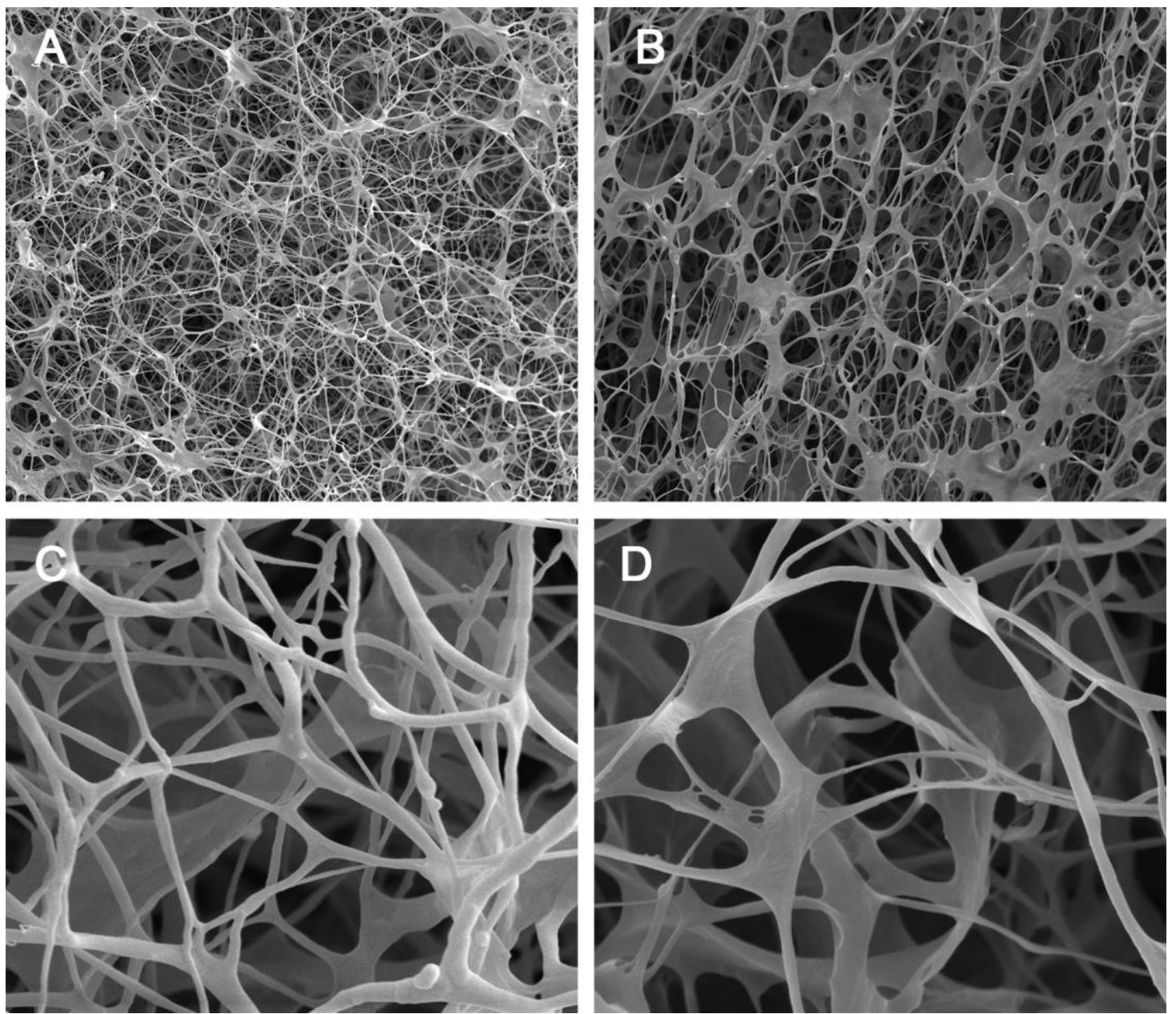

Fig.2. SEM images of $4 \mathrm{mg}$ collagen gels $(A, C)$ and $4 \mathrm{mg}$ with $T G 2(B, D)$ acquired at $6.000 X--50.000 X$ magnifications (first and second row respectively) showing the morphological features of the hydrogel fibers.

To confirm this, we analyzed the alignment of the networks of different hydrogels obtaining the alignment index, ranging from 0 (completely isotropic structure) to 1

This is the post-print version of the following article: Movilla, N., Borau, C., Valero, C., \& García-Aznar, J. M. (2018). Degradation of extracellular matrix regulates osteoblast migration: A microfluidic-based study. Bone, 107, 10-17. doi: 10.1016/j.bone.2017.10.025, which has been published in final form here. 
(completely aligned structure). Figure 3 shows that hydrogel networks without TG2 are significantly less aligned (alpha about 0.4 , compared to 0.6 ).

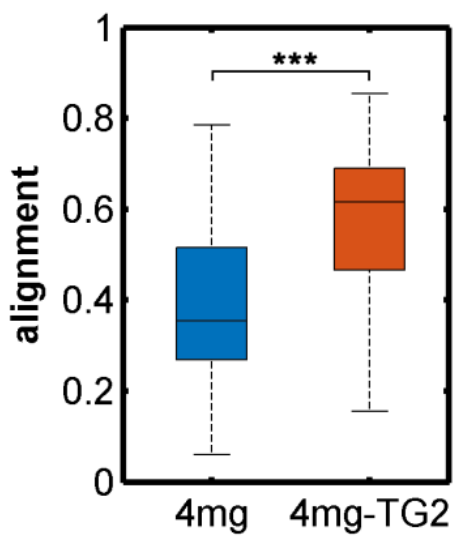

Fig.3. Alignment index of $4 \mathrm{mg}$ and $4 \mathrm{mg}$ (with TG2) collagen-based gels. When this index is (0 represents: totally isotropic networks and 1: fully aligned ones. Hydrogel networks with TG2 were significantly more aligned than those without. 3 replicates were done for each condition taking up to 28 images from different scaffolds per replicate at different magnifications. ${ }^{* *} p<0.001 ;{ }^{* *} p<0.01 ;{ }^{*} p<0.05$.

\section{2. $H O B$ migration is almost unaltered under PDGF-BB gradients.}

We examined the effect of PDGF-BB isoform on osteoblast migration under two different concentrations: $5 \mathrm{ng} / \mathrm{ml}$ and $50 \mathrm{ng} / \mathrm{ml}$. We did not find any significant alteration of cell orientation in the direction of the gradient, but we found a migration stimulation effect on the cell velocities at the lower dose that increased the mean and effective speeds, whereas the higher concentration, probably due to an inhibitory effect, presented values very similar to, and even lower than control (Figure 4A). The median of the estimated diffusion coefficient (D) corroborated this trend, obtaining values of $1.199 \mathrm{\mu m}^{2} / \mathrm{min}$ under control conditions and $1.605 \mu \mathrm{m}^{2} / \mathrm{min}$ and 0.913 $\mu \mathrm{m}^{2} / \mathrm{min}$ for $5 \mathrm{ng} / \mathrm{ml}$ and $50 \mathrm{ng} / \mathrm{ml}$ concentrations respectively (Figure 4B). Nevertheless, the directionality slightly increases at higher doses of PDGF-BB during the whole experiment (Figure 4C).
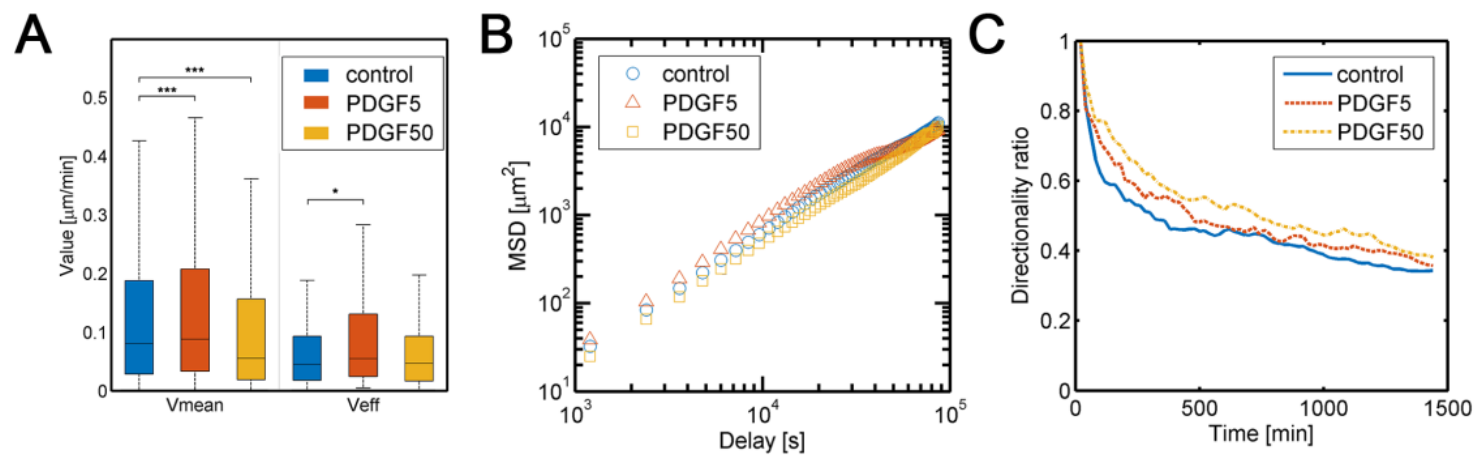

This is the post-print version of the following article: Movilla, N., Borau, C., Valero, C., \& García-Aznar, J. M. (2018). Degradation of extracellular matrix regulates osteoblast migration: A microfluidic-based study. Bone, 107, 10-17. doi: 10.1016/j.bone.2017.10.025, which has been published in final form here. 
Fig.4. (A) Mean and effective speeds of $\mathrm{HOB}$ cells, (B) mean squared displacement (MSD) of tracked trajectories and (C) directionality ratio of $4 \mathrm{mg} / \mathrm{ml}$ of collagen with 0 (control, blue), 5 (orange) and 50 (yellow) $\mathrm{ng} / \mathrm{ml}$ PDGF-BB. $5 \mathrm{ng} / \mathrm{ml}$ concentration was used in four independent experiments with three technical replicas each, and $50 \mathrm{ng} / \mathrm{ml}$ concentration was used in two independent experiments with three technical replicas each $* * * p<0.001 ; * *<0.01 ; \mathrm{*}<0.05$.

\subsection{TG2 crosslinked collagen hydrogels enhance directional HOB migration but do not} affect the motility.

Collagen hydrogels were treated with TG2 to study the effect of crosslinked networks on cell migration. Results showed that although statistically significant differences were found regarding mean and effective speeds in TG2 collagens compared to control, these variations were not relevant, the median of the instantaneous speed ( $v_{\text {mean }}$ ) being $0.080 \mu \mathrm{m} / \mathrm{min}$ in control cells and $0.075 \mu \mathrm{m} / \mathrm{min}$ in TG2 treated hydrogels. In the case of effective speed ( $v_{\text {eff, }}$ which takes into account only the first and last points of the trayectory) we obtained a median value of $0.044 \mu \mathrm{m} / \mathrm{min}$ versus $0.068 \mu \mathrm{m} / \mathrm{min}$ in TG2 treated hydrogels (Figure 5A). The diffusion coefficient was enhanced with TG2, obtaining a median value of $1.747 \mu \mathrm{m}^{2} / \mathrm{min}$ compared to 1.199 $\mu \mathrm{m}^{2} /$ min of controls (Figure $5 \mathrm{~B}$ ), as well as the directionality ratio throughout all the recorded period (Figure $5 \mathrm{C}$ ). To further confirm this, we increased the concentration of TG2 to $50 \mu \mathrm{g} / \mathrm{ml}$ finding that it did not significantly change neither the alignment (Fig S5) nor the velocity and directionality of $\mathrm{HOB}$ cells compared to those obtained for $25 \mu \mathrm{g} / \mathrm{ml}$ (Fig S6). These results together implied that TG2 favored directed migration, probably due to a higher network alignment as suggested by the microstructural study (Figure 3). We also observed a higher auto-correlation of cell velocities with TG2 that indicated that cell movements were more persistent (Fig S1).
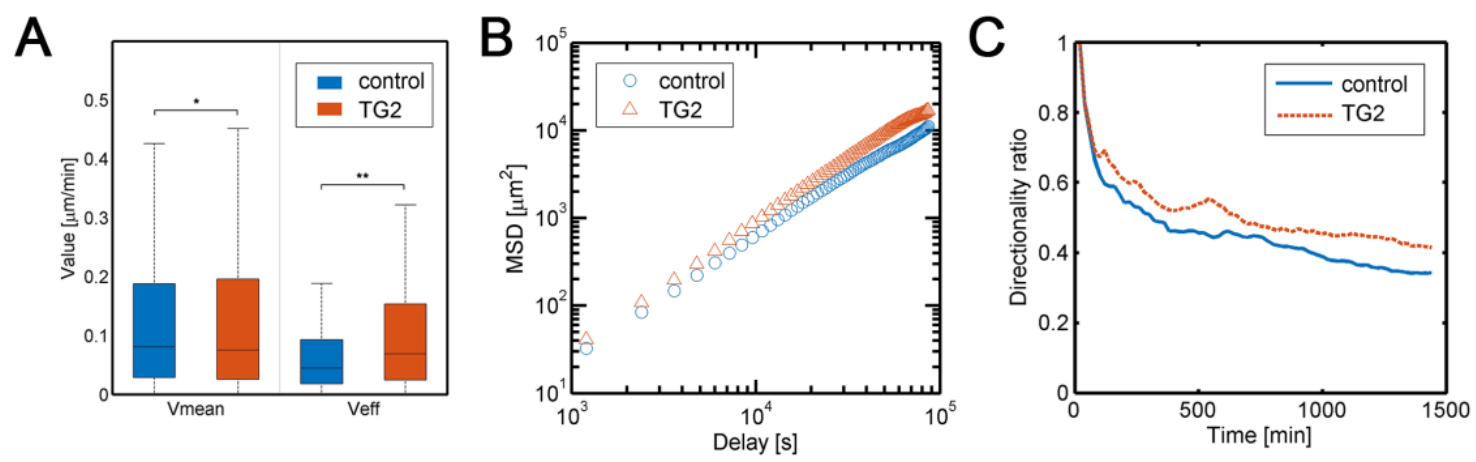

Fig.5. (A) Mean and effective speeds of $\mathrm{HOB}$ cells, (B) mean squared displacement (MSD) of tracked trajectories and $(C)$ directionality ratio on $4 \mathrm{mg} / \mathrm{ml}$ collagen with (orange curve) and without (blue curve) TG2. $25 \mu \mathrm{g} / \mathrm{ml}$ TG2 were used in four independent experiments with three technical replicas each. $* * * p<0.001 ; * * p<0.01 ; * p<0.05$.

\section{4. $H O B$ migration in $3 D$ is highly anisotropic}

This is the post-print version of the following article: Movilla, N., Borau, C., Valero, C., \& García-Aznar, J. M. (2018). Degradation of extracellular matrix regulates osteoblast migration: A microfluidic-based study. Bone, 107, 10-17. doi: 10.1016/j.bone.2017.10.025, which has been published in final form here. 
Cell trajectories, relative to their origin, of multiple assays were analyzed together to elucidate whether there existed directional patterns depending on the conditions. As shown in Figure 6 , both in the real trajectories and the polar histograms, we did not find any visible pattern even though some of the cases presented a factor gradient in a specific direction or a higher alignment of the fibers. This suggested that although chemical or microstructural conditions may enhance motility in 3D, it is still hard for the cells to follow a straight path, i.e. towards the chemical source. However, a deeper analysis of cell trajectories by decomposing the movements into a main and a secondary direction (Pei-Hsun et al, 2015), revealed that cell migration in 3D is intrinsically highly anisotropic regardless of the conditions (Figure 7). That is, although the overall cell movement looks random, each specific cell moves preferably in a certain direction, probably guided by the three-dimensional microstructure surrounding it. Hence, major changes on this microstructure would be critical to determine the migration. In fact, the anisotropic index was indirectly calculated via the diffusion coefficients in both the primary and secondary directions of migration, and the results showed high values for all the studied cases (Figure S2).
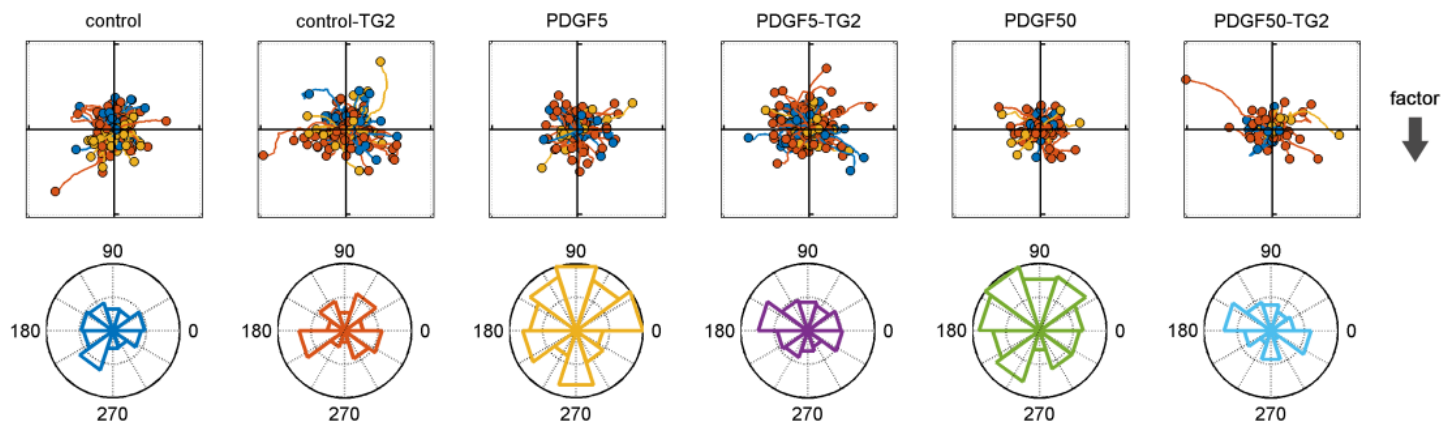

Fig.6. Trajectories of individual cells (first row) and polar histograms (second row). Colors on trajectories are only used for visualization purposes. Histograms show the angular distribution of the trajectories taking into account only the first and last point of each trajectory. Factor gradient direction is indicated by a black arrow.

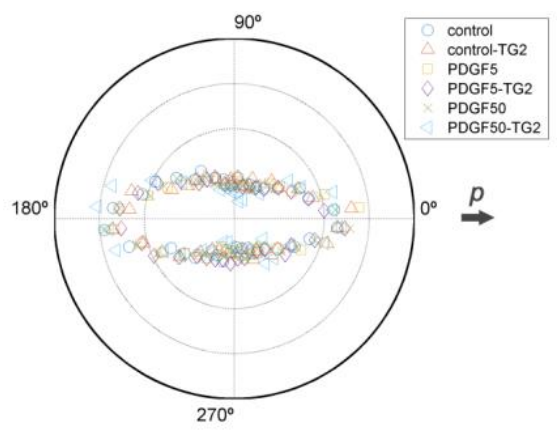

Fig.7. Velocity magnitude polarization profile: average magnitude of cell speed, re-aligned along the primary migration direction $(p)$ and evaluated at different orientations. If the velocity is isotropic (a true random walk) the average magnitude of cell speed is equally likely in all directions. Results show that the average magnitude along the primary migration direction was substantially higher than that along other directions for all the studied cases, revealing an intrinsically anisotropic behavior.

This is the post-print version of the following article: Movilla, N., Borau, C., Valero, C., \& García-Aznar, J. M. (2018). Degradation of extracellular matrix regulates osteoblast migration: A microfluidic-based study. Bone, 107, 10-17. doi: 10.1016/j.bone.2017.10.025, which has been published in final form here. 


\subsection{HOB degradation capacity is essential for migration}

To analyze the importance of matrix degradability we treated HOB cells with the MMP inhibitor, Marimastat $(10 \mu \mathrm{M})$, which blocks the ECM degradation activity (Fraley et al, 2015). We found a very strong effect on HOB migration, dramatically reducing the median values of both mean and effective speeds (Figure 8A). In fact, in some cases cells did not move at all. Consequently, the diffusion coefficient was drastically reduced (median values from $0.927 \mathrm{\mu m}^{2} / \mathrm{min}$ to $0.145 \mu \mathrm{m}^{2} / \mathrm{min}$ ) as well as the directionality ratio that almost dropped to values around $0.227 \mu \mathrm{m}^{2} / \mathrm{min}$ (Figure $8 \mathrm{~B}$ and $8 \mathrm{C}$ ) in comparison with $0.390 \mu \mathrm{m}^{2} / \mathrm{min}$ in the control case.
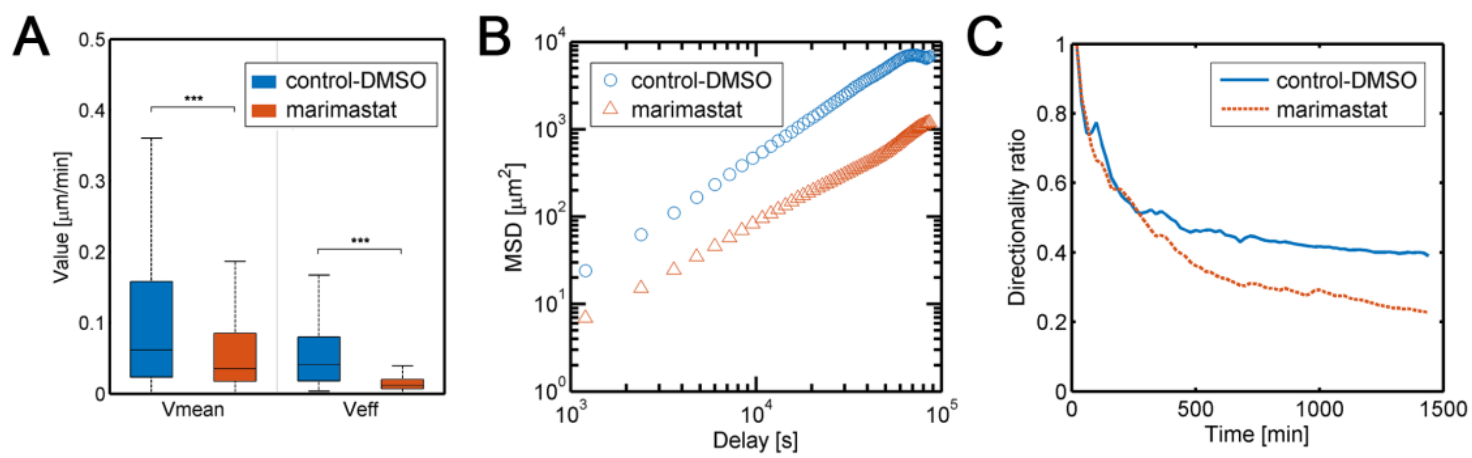

Fig.8. (A) Mean and effective speeds of $\mathrm{HOB}$ cells, (B) mean squared displacement (MSD) of tracked trajectories and (C) directionality ratio for collagen hydrogels with (orange) and without (blue) Marimastat. The experiments were repeated twice with 3 replicates each experiment. ${ }^{* * *} p<0.001$; $* * p<0.01 ; * p<0.05$.

To further confirm this, we also tested the MMP inhibitor with gels crosslinked with TG2. As in the cases without crosslinking, the addition of Marimastat had strong effects on osteoblast speed (both instantaneous and effective, figure 9A) as well as on the diffusion coefficient (median values of $1.255 \mu \mathrm{m}^{2} / \mathrm{min}$ compared to 0.191 $\mu \mathrm{m}^{2} / \mathrm{min}$, figure $9 \mathrm{~B}$ ) and the directionality ratio (Figure $9 \mathrm{C}$ ). Therefore, from our results we observe that although TG2 makes the gel more resistant to proteolysis (Chay et al, 2005; Jones et al, 2006), cells are able to selectively degrade extracellular matrix in order to define its movement.

In addition, gelatin zymography showed that in the presence of inhibitor marimastat, metalloproteinase MMP9 accumulated clearly in its inactive latent form (Fig S7 and S8), a result coherent with inhibition of cell migration, suggesting that HOB migration was highly regulated by degradation of the ECM. 

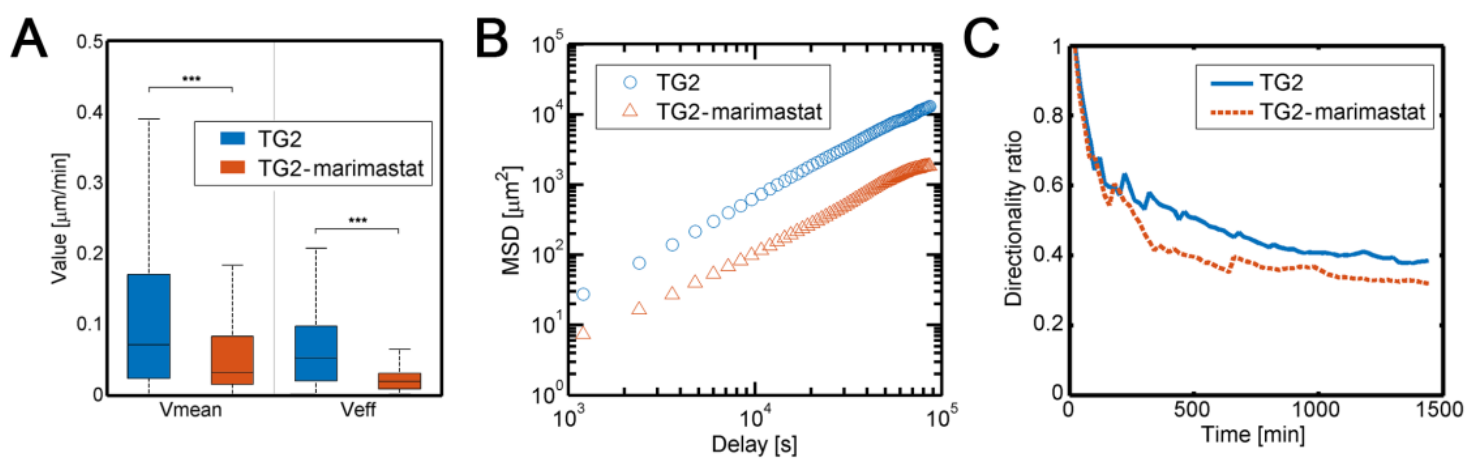

Fig.9. (A) Mean and effective speeds of $\mathrm{HOB}$ cells, (B) mean squared displacement (MSD) of tracked trajectories and (C) directionality ratio for collagen hydrogels with TG2 and with (orange) and without (blue) marimastat. The experiment was repeated once with 3 replicates. ${ }^{* * *} p<0.001 ; * * p<0.01$; $* p<0.05$.

Tables 2 and 3 summarize the median values of mean and effective speeds, directionality ratio and motility parameters (diffusion coefficient, persistence time and persistence speed extracted from the adjusted PRW and APRW models).

\section{Conclusions}

In this work, we show that osteoblasts present a relevant potential to migrate in 3D, and for the first time quantify such migration. By comparing the effect of collagen cross-linking, we observed small but significant differences, especially regarding speeds and directionality, when the collagen network was cross-linked with TG2. In fact, the addition of TG2 did not affect cell speeds appreciably, but enhanced the diffusivity and directionality, probably due to the higher fiber alignment found in these networks (Figure 3). Nevertheless, other factors such as porosity and network strength should be further explored to elucidate the specific roles on cell migration capacity. On the other hand, with respect to the effect of chemical gradients, we also found that PDGF-BB presents a low chemoattractant potential for osteoblasts compared for instance to its effect on fibroblasts (Moreno-Arotzena et al, 2015). In fact, even high concentrations of PDGF-BB didn't result in a much faster, nor directional migration of osteoblasts compared to control cases. This fact could indicate that PDGF-BB is more relevant in wound healing processes rather than in bone healing ones, although we have to keep in mind that physiological environments are subject to many other factors that have not been included in this experimental model. Additionally, we studied the influence of Marimastat, a broad-spectrum metalloproteinase inhibitor, which lead to drastic changes in cell motility, significantly decreasing speeds, diffusivity and directionality. This effect was present in both types of hydrogels (with and without TG2), suggesting that matrix degradation plays the most important role among all the studied factors. This agrees with the findings from Ehrbar et al (2011), which used 
polyethylene glycol-based matrices with different concentrations and concluded that a non-proteolytic migration mode dominates at relatively low concentrations and proteolytic migration at higher ones. In their work, authors observed migration velocities of $0.6 \mu / \mathrm{min}$ (in non-degradable matrices) and $0.9 \mu / \mathrm{min}$ (in degradable ones) at lower gel concentrations, due to the larger porosities of these gels. However, at higher concentrations $(2.5 \%)$ they obtained migration velocities of the same order than us (around $0.1 \mu \mathrm{m} / \mathrm{min}$ ), again suggesting that the mode of osteoblast migration was predominantly governed by proteolysis in the physiological 3D collagen-based gels.

Therefore, from our work we conclude that the combination of network fiber alignment and the ability to degrade the ECM are the fundamental mechanisms regulating osteoblast individual 3D migration. In this sense, cells could react to other cues such as chemical factors or stiffness for instance by varying the number of protrusions or tweaking the strength of the adhesions, but would be ultimately dependent on the microstructure and the geometry of the surrounding paths. This would also explain why 3D cell migration is intrinsically anisotropic, regardless of the mechano-chemical conditions (Figure 7). This implies, as suggested by Pei-Hsun et al (2014) that 3D migration does not follow a random walk, and therefore that anisotropic persistent random walk models (APRW) should be used when dealing with this kind of studies instead of the classic PRW models commonly used in 2D. Mainly, this effect appears because cell migration in 3D matrices requires mechanisms of force generation, cell-matrix adhesion, and signaling pathways that are distinct from those required for 2D migration ( $\mathrm{Wu}$ et al, 2015). However, migration on 2D is driven by actomyosin contractility and large focal adhesions. Further, 3D cell migration is tightly associated with the expression of metalloproteinases (MMPs) and architecture of the 3D matrix, which are more dispensable in 2D migration. Although we evaluated our results using both PRW and APRW models and the obtained values were similar (see Table 3 and Figures S2, S3 and S4), this finding might totally change the focus in future studies when it comes to analyze patterns or key phenomena in relevant processes such as cancer metastasis involving matrix degradation, dendritic protrusions, different migratory phenotypes or, in short, 3D migration through a complex network.

Finally, it is important to remark that the hydrogels here used, present a low collagen concentration $(4 \mathrm{mg} / \mathrm{ml})$, because we focus on recreating the granulation tissue, which is defined as a soft unmineralized tissue that appears during the bone healing process (Loi et al, 2016) and where the migratory process occurs swiftly due to the need to recover the mechanical stability of the fracture gap as soon as possible. In fact, within a few hours after fracture, the extravascular blood cells form a blood clot, known as a 
hematoma. After several days, when this hematoma and the subsequent acute inflammatory reaction are cleared, they are replaced by granulation tissue with a developing neovasculature embedded in an unorganized extracellular collagen matrix (Marsell et al, 2011). This granulation tissue gives mechanical support to osteoblasts and proliferative mesenchymal cells to allow their migration, reducing strain across the fracture site and favoring the reparative phase (Claes et al, 2012). Certainly, migratory patterns could be strongly altered by using stiffer matrices with higher collagen concentration (e.g. $40 \mathrm{mg} / \mathrm{ml}$ ) or by including bone apatite in the matrix (Robin et al, 2016). Our hydrogels, however, with a much lower concentration of collagen, exhibit large interfibrillar spaces which can be easily degraded by proteases and hence facilitate cell motility. In any case, the mechanical properties measured in pure dense collagen matrices (15 kPa) are close to those reported for the osteoid tissue (about 25 kPa (Engler et al, 2006; Buxton et al, 2008)) and therefore allow recreating the osteoblast invasion of the osteoid, which is more habitual in bone remodeling phenomena (Uchihasi et al, 2013; Robin et al, 2016).

To conclude, our method for recreating the bone healing microenvironment, together with our workbench of image processing and quantification, presents a promising tool to analyze the effect of different biophysical and chemical conditions on the migration of osteoblastic cells in vitro. Actually, microfluidics allows bridging the existent gap between $2 \mathrm{D}$ cultures and animal models by recreating some of the complex features of the in-vivo microenvironment (Shin et al, 2012). Understanding how the environmental conditions can regulate the directional migration of osteoblasts is of great importance for bone therapies in the treatment of osteoporosis or in the development of novel bone tissue engineering strategies. As these microfluidic chips constitute a flexible tool that provides advantages beyond those offered by existing culture systems in tissue engineering, these microphysiological systems potentially could be created using combination of different materials, soluble factors or specific cell co-cultures, thereby permitting in-vitro tests of different tissue engineering strategies.

\begin{tabular}{|c|c|c|c|c|}
\hline HOB Condition & $\begin{array}{c}\boldsymbol{v}_{\text {mean }} \\
(\mu \mathrm{m} / \mathrm{min})\end{array}$ & $\begin{array}{c}\boldsymbol{v}_{\text {eff }} \\
(\mu \mathrm{m} / \mathrm{min})\end{array}$ & $\mathbf{d R}$ & $\mathbf{D}\left(\mu \mathrm{m}^{\mathbf{2}} / \mathrm{min}\right)$ \\
\hline Control & 0.080 & 0.044 & 0.343 & 1.199 \\
\hline Control-TG2 & 0.075 & 0.068 & 0.415 & 1.747 \\
\hline Control-DMSO & 0.061 & 0.041 & 0.390 & 0.927 \\
\hline PDGF 5 & 0.087 & 0.055 & 0.357 & 1.605 \\
\hline PDGF 5-TG2 & 0.070 & 0.068 & 0.428 & 1.623 \\
\hline
\end{tabular}

This is the post-print version of the following article: Movilla, N., Borau, C., Valero, C., \& García-Aznar, J. M. (2018). Degradation of extracellular matrix regulates osteoblast migration: A microfluidic-based study. Bone, 107, 10-17. doi: 10.1016/j.bone.2017.10.025, which has been published in final form here. 


\begin{tabular}{|c|c|c|c|c|}
\hline PDGF 50 & 0.055 & 0.046 & 0.381 & 0.913 \\
\hline PDGF 50-TG2 & 0.078 & 0.075 & 0.472 & 2.293 \\
\hline Marimastat & 0.035 & 0.012 & 0.227 & 0.145 \\
\hline Marimastat-TG2 & 0.032 & 0.019 & 0.320 & 0.191 \\
\hline
\end{tabular}

Table 2. Median values of the mean and effective speeds $\left(v_{\text {mean }}, v_{\text {eff }}\right)$, directionality ratio $(\mathrm{dR})$ and diffusivity coefficient (D).

\begin{tabular}{|c|c|c|c|c|c|c|c|c|c|c|c|}
\hline \multirow[b]{3}{*}{$\begin{array}{l}\text { HOB } \\
\text { condition }\end{array}$} & \multicolumn{3}{|c|}{$\begin{array}{c}\text { Persistence time } \\
\text { (min) }\end{array}$} & \multicolumn{3}{|c|}{$\begin{array}{c}\text { Persistence speed } \\
(\mu \mathrm{m} / \mathrm{min})\end{array}$} & \multicolumn{4}{|c|}{ Diffusivity $\left(\mu \mathrm{m}^{2} / \mathrm{min}\right)$} & \multirow{3}{*}{$\begin{array}{c}\begin{array}{c}\text { Anisotropic } \\
\text { index }\end{array} \\
\text { APRW } \\
\left(D_{p} / D_{n p}\right)\end{array}$} \\
\hline & \multirow{2}{*}{$\begin{array}{c}\text { PRW } \\
\text { P }\end{array}$} & \multicolumn{2}{|c|}{ APRW } & \multirow{2}{*}{$\frac{\text { PRW }}{\mathrm{S}}$} & \multicolumn{2}{|c|}{ APRW } & \multirow{2}{*}{$\frac{\text { PRW }}{\text { D }}$} & \multicolumn{3}{|c|}{ APRW } & \\
\hline & & $\mathbf{P}_{\mathrm{p}}$ & $\mathbf{P}_{\mathrm{np}}$ & & $S_{p}$ & $S_{n p}$ & & $D_{p}$ & $D_{n p}$ & $D_{\text {total }}$ & \\
\hline Control & 37.162 & 42.562 & 2.419 & 0.245 & 0.299 & 0.181 & 0.841 & 0.788 & 0.038 & 0.937 & 13.211 \\
\hline Control-TG2 & 46.797 & 50.214 & 5.400 & 0.253 & 0.325 & 0.183 & 1.111 & 0.888 & 0.0638 & 1.177 & 14.797 \\
\hline $\begin{array}{l}\text { Control- } \\
\text { DMSO }\end{array}$ & 34.678 & 44.400 & 5.581 & 0.188 & 0.239 & 0.153 & 0.464 & 0.440 & 0.031 & 0.513 & 13.211 \\
\hline PDGF 5 & 37.362 & 45.278 & 12.387 & 0.275 & 0.343 & 0.184 & 0.875 & 0.794 & 0.082 & 0.951 & 11.087 \\
\hline PDGF 5-TG2 & 36.233 & 39.311 & 16.240 & 0.267 & 0.334 & 0.185 & 1.048 & 0.941 & 0.092 & 1.119 & 9.557 \\
\hline PDGF 50 & 30.037 & 36.151 & 12.800 & 0.227 & 0.285 & 0.148 & 0.557 & 0.526 & 0.049 & 0.587 & 11.209 \\
\hline $\begin{array}{l}\text { PDGF 50- } \\
\text { TG2 }\end{array}$ & 36.777 & 41.058 & 4.868 & 0.289 & 0.378 & 0.210 & 1.203 & 1.248 & 0.077 & 1.326 & 13.829 \\
\hline Marimastat & 5.558 & 9.852 & 1.854 & 0.154 & 0.171 & 0.128 & 0.063 & 0.051 & 0.012 & 0.066 & 4.608 \\
\hline $\begin{array}{l}\text { Marimastat- } \\
\text { TG2 }\end{array}$ & 24.083 & 30.104 & 3.051 & 0.119 & 0.136 & 0.098 & 0.109 & 0.086 & 0.013 & 0.115 & 7.292 \\
\hline
\end{tabular}

Table 3. Median values of persistence time $(P)$, persistence speed $(S)$ and diffusion coefficient $(D)$ fitted with the PRW and APRW models. The APRW fitting produces two values for each parameter, one for the primary axis of cell migration (subindex $p$ ) and one for the nonprimary axis (subindex $n p$ ). The anisotropic index is obtained as the ratio between $D_{\mathrm{p}}$ and $D_{\mathrm{np}}$.

\section{Acknowledgements}

This study was supported by the European Research Council (ERC) through project ERC-2012-StG 306571 and the Spanish Ministry of Economy and Competitiveness through the project DPI2015-64221-C2-1-R. The authors also acknowledge Dr. Roger Kamm for the technical assistance with the development of microfluidic techniques, Carlos Cuestas for SEM analysis and Giuseppe Lattanzio from Proteomics Unit of Scientific Technical Services of CIBA (IACS- University of Zaragoza), ProteoRed ISCIII member for gel zymography.

\section{References}

Bersini S, Jeon JS, Dubini G, Arrigoni C, Chung S, Charest JL, Moretti M, Kamm RD. A microfluidic 3D in vitro model for specificity of breast cancer metastasis to bone. Biomaterials, 2014; Mar;35(8):2454-61. 
Borau C, Kamm RD, García-Aznar JM. Mechano-sensing and cell migration: a 3D model approach. Phys Biol. 2011 Dec;8(6).

Boussommier-Calleja A, Li R, Chen MB, Wong SC, Kamm RD. Microfluidics: A new tool for modeling cancer-immune interactions. Trends Cancer, 2016; Jan 1;2(1):6-19.

Buxton P.G., Bitar M., Gellynck K., Parkar M., Brown R.A., Young A.M., Knowles J.C., Nazhat S.N. Dense collagen matrix accelerates osteogenic differentiation and rescues the apoptotic response to MMP inhibition, Bone 43, 2008; 377-385.

Byrne DP, Lacroix D, Prendergast PJ. Simulation of fracture healing in the tibia: mechanoregulation of cell activity using a lattice modeling approach. J Orthop Res, 2011.

Casati, L., Celotti, F., Negri-Cesi, P., Sacchi, M. C., Castano, P., \& Colciago, A. Platelet derived growth factor (PDGF) contained in Platelet Rich Plasma (PRP) stimulates migration of osteoblasts by reorganizing actin cytoskeleton. Cell adhesion \& migration, 2014; 8(6), 595-602.

Chau, D.Y.S., Collighan, R.J., Verderio E.A.M., Addy V. L., Griffin M. The cellular response to transglutaminase-cross-linked collagen. Biomaterials, 2005;26,6518-6529.

Chen MB, Whisler JA, Fröse J, Yu C, Shin Y, Kamm RD.On-chip human microvasculature assay for visualization and quantification of tumor cell extravasation dynamics.

Nat Protoc. 2017 May;12(5):865-880.

Claes, L., Recknagel, S., \& Ignatius, A. Fracture healing under healthy and inflammatory conditions. Nature Reviews Rheumatology, 2012; 8(3), 133-143.

Dee, K. C., Andersen, T. T., \& Bizios, R. Osteoblast population migration characteristics on substrates modified with immobilized adhesive peptides. Biomaterials, 1999; 20(3), 221-227.

Del Amo C., Borau C. Gutiérrez R., Asín J., García-Aznar JM. Quantification of angiogenic sprouting under different growth factors in a microfluidic platform. J Biomech. 2016 May 24;49(8):1340-6.

DiGiovanni C.W., Lin S.S., Baumhauer J.F., Daniels T., Younger A., Glazebrook M., Anderson J., Anderson R., Evangelista P., Lynch S.E. Recombinant Human PlateletDerived Growth Factor-BB and Beta-Tricalcium Phosphate (rhPDGF-BB/ $\beta-T C P$ ): An Alternative to Autogenous Bone Graft, The Journal of Bone \& Joint Surgery 95(13) 2013; 1184-1192.

Doyle, A. D., Petrie, R. J., Kutys, M. L., \& Yamada, K. M. (2013). Dimensions in cell migration. Current opinion in cell biology, 25(5), 642-649.

This is the post-print version of the following article: Movilla, N., Borau, C., Valero, C., \& García-Aznar, J. M. (2018). Degradation of extracellular matrix regulates osteoblast migration: A microfluidic-based study. Bone, 107, 10-17. doi: 10.1016/j.bone.2017.10.025, which has been published in final form here. 
Ehrbar, M., Sala, A., Lienemann, P., Ranga, A., Mosiewicz, K., Bittermann, A., ... \& Lutolf, M. P. (2011). Elucidating the role of matrix stiffness in 3D cell migration and remodeling. Biophysical journal, 100(2), 284-293.

Elsdale T, Bard J. Collagen substrata for studies on cell behavior. J Cell Biol, 1972; 54:626-37.

Engler AJ, Sen S, Sweeney HL, Discher DE. Matrix elasticity directs stem cell lineage specification. Cell. 2006 Aug 25;126(4):677-89.

Farahat WA, Wood LB, Zervantonakis IK, Schor A, Ong S, Neal D, Kamm RD, Asada HH: Ensemble analysis of angiogenic growth in three-dimensional microfluidic cell cultures. PLoS One 2012, 7:e37333.

Fraley S.I., Wu PH., He L., Feng Y., Krisnamurthy R., Longmore G.D., Wirtz D. Threedimensional matrix fiber alignment modulates cell migration and MT1-MMP utility by spacilly and temporally directing protrusions. Scientific Reports. 2015, 14580.

Giorgi, M., Verbruggen, S. W., \& Lacroix, D. In silico bone mechanobiology: modeling a multifaceted biological system. Wiley Interdisciplinary Reviews: Systems Biology and Medicine; 2016.

Gómez-Benito MJ, García-Aznar JM, Kuiper JH, Doblaré M. Influence of fracture gap size on the pattern of long bone healing: a computational study. J Theor Biol. $2005 \mathrm{Jul}$ 7;235(1):105-19.

Gorelik R, Gautreau A. Quantitative and unbiased analysis of directional persistence in cell migration. Nat Protoc.2014 Aug;9(8):1931-43.

Hengartner, N. E., Fiedler, J., Ignatius, A., \& Brenner, R. E. IL-1ß Inhibits Human Osteoblast Migration. Mol Med, 2013; 19, 36-42.

Hollinger J.O., Hart C.E., Hirsch S.N., Lynch S., Friedlaender G.E., Recombinant Human Platelet-Derived Growth Factor: Biology and Clinical Applications, The Journal of Bone \& Joint Surgery 90(Supplement 1) 2008; 48-54.

Ishaug, S. L., Payne, R. G., Yaszemski, M. J., Aufdemorte, T. B., Bizios, R., \& Mikos, A. G. Osteoblast migration on poly ( $\alpha$-hydroxy esters). Biotechnology and bioengineering, 1996; 50(4), 443-451.

Jones RA, Kotsakis P, Johnson TS, Chau DY, Ali S, Melino G, Griffin M Matrix changes induced by transglutaminase 2 lead to inhibition of angiogenesis and tumor growth. Cell Death Differ, 2006; 13(9):1442-1453. 
Koppenol, D. C., Vermolen, F. J., Niessen, F. B., van Zuijlen, P. P., \& Vuik, K. (2016). A biomechanical mathematical model for the collagen bundle distribution-dependent contraction and subsequent retraction of healing dermal wounds. Biomechanics and Modeling in Mechanobiology, 1-17.

Lind M, Deleuran B, Thestrup-Pedersen K, S+balle K, Eriksen EF, Bünger C. Chemotaxis of human osteoblasts. Effects of osteotropic growth factors. APMIS 1995;103(2):140-6.

Loi, F., Córdova, L. A., Pajarinen, J., Lin, T. H., Yao, Z., \& Goodman, S. B. Inflammation, fracture and bone repair. Bone, 2016; 86, 119-130.

Lucas PA. Chemotactic response of osteoblast-like cells to transforming growth factor beta. Bone, 1989;10:459-63.

Marsell, R., \& Einhorn, T. A. The biology of fracture healing. Injury, 2011;42(6), 551555.

Mehrotra M, Krane SM, Walters K, Pilbeam C. Differential regulation of plateletderived growth factor stimulated migration and proliferation in osteoblastic cells. J. Cell. Biochem.2004; 93:741-52.

Moreno-Arotzena, O., Borau, C., Movilla, N., Vicente-Manzanares, M., \& García-Aznar, J. M. Fibroblast Migration in 3D is Controlled by Haptotaxis in a Non-muscle Myosin IIDependent Manner. Annals of biomedical engineering, 2015; 43(12), 3025-3039.

Moreno-Arotzena, O., Mendoza, G., Cóndor, M., Rüberg, T., \& García-Aznar, J. M. Inducing chemotactic and haptotactic cues in microfluidic devices for threedimensional in vitro assays. Biomicrofluidics, 2014; 8(6), 064122.

Mullen CA, Vaughan TJ, Billiar KL, McNamara LM. The Effect of Substrate Stiffness, Thickness, and Cross-Linking Density on Osteogenic Cell Behavior. Biophysical Journal, 2015; Apr 7;108(7):1604-12.

Nakasaki M, et al. IGF-I secreted by osteoblasts acts as a potent chemotactic factor for osteoblasts. Bone, 2008; 43:869-79.

Petrie, R. J., Gavara, N., Chadwick, R. S., \& Yamada, K. M. (2012). Nonpolarized signaling reveals two distinct modes of $3 \mathrm{D}$ cell migration. The Journal of cell biology, 197(3), 439-455.

Polacheck WJ ${ }^{1}$, Charest JL, Kamm RD. Interstitial flow influences direction of tumor cell migration through competing mechanisms. Proc Natl Acad Sci U S A. 2011; Jul 5;108(27):11115-20. 
Ribeiro FO, Gómez-Benito MJ, Folgado J, Fernandes PR, García-Aznar JM. In silico Mechano-Chemical Model of Bone Healing for the Regeneration of Critical Defects: The Effect of BMP-2. PLoS One, 2015;Jun 4;10(6).

Ribeiro, F. O., Gómez-Benito, M. J., Folgado, J., Fernandes, P. R., \& García-Aznar, J. M. (2016). Computational model of mesenchymal migration in 3D under chemotaxis. Computer Methods in Biomechanics and Biomedical Engineering, 2017; $\operatorname{Jan}(1): 59-74$.

Robin M, Almeida C, Azaïs T, Haye B, Illoul C, Lesieur J, Giraud-Guille MM, Hélary C. Involvement of $3 \mathrm{D}$ osteoblast migration and bone apatite during in vitro early osteocytogenesis , 2016; Jul;88:146-56.

Sander EA, Barocas VH. Comparison of 2D fiber network orientation measurement methods. J Biomed Mater Res A. 2009 Feb;88(2):322-31

Shin Y, Han S, Jeon JS, Yamamoto K, Zervantonakis IK, Sudo R, Kamm RD, Chung S: Microfluidic assay for simultaneous culture of multiple cell types on surfaces or within hydrogels. Nat Protoc, 2012; 7:1247-59.

Silvent J., Nassif N., Helary C., Azais T., Sire J.-Y., Giraud-Guille M.M. Collagen osteoidlike model allows kinetic gene expression studies of non-collagenous proteins in relation with mineral development to understand bone biomineralization. PLoS One 8 , 2013; e57344.

Scott K.A., Wood E.J., Karran E.H. A matrix metalloproteinase inhibitor which prevents fibroblast-mediated collagen lattice contraction. FEBS Letters 441, 1998, 137-140.

Uchihashi, K., Aoki, S., Matsunobu, A., \& Toda, S. Osteoblast migration into type I collagen gel and differentiation to osteocyte-like cells within a self-produced mineralized matrix: a novel system for analyzing differentiation from osteoblast to osteocyte. Bone, 2013; 52(1), 102-110.

Valero, C., Javierre, E., García-Aznar, J. M., Menzel, A., \& Gomez-Benito, M. J. Challenges in the modeling of wound healing mechanisms in soft biological tissues. Annals of biomedical engineering, 2015; 43(7), 1654-1665.

Wu PH, Giri A, Wirtz D. Statistical analysis of cell migration in 3D using the anisotropic persisten random walk model. Nat Protoc. 2015; Mar;10(3):517-27.

\section{SUPPLEMENTARY FIGURES}

This is the post-print version of the following article: Movilla, N., Borau, C., Valero, C., \& García-Aznar, J. M. (2018). Degradation of extracellular matrix regulates osteoblast migration: A microfluidic-based study. Bone, 107, 10-17. doi: 10.1016/j.bone.2017.10.025, which has been published in final form here. 


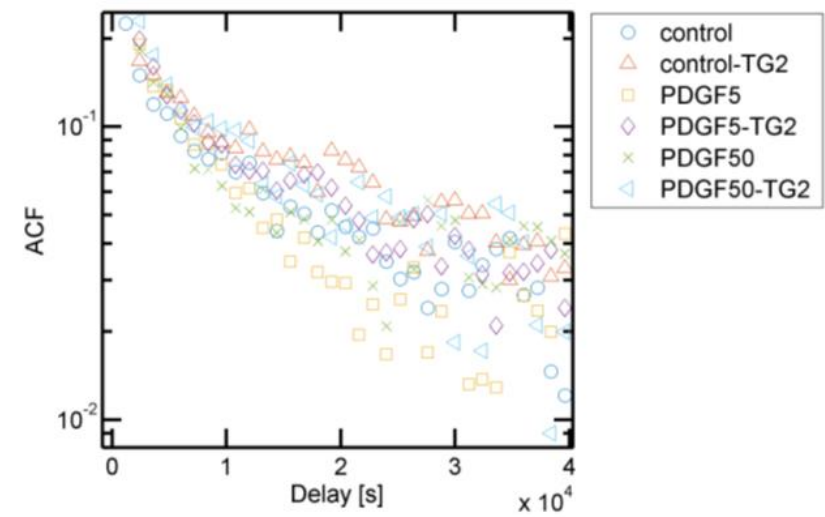

Fig.S1. Auto- correlation function of cell velocities (ACF). A higher value indicates that cell movements are more persistent. ACF approaching 0 indicates that cells follow random walk statistics.

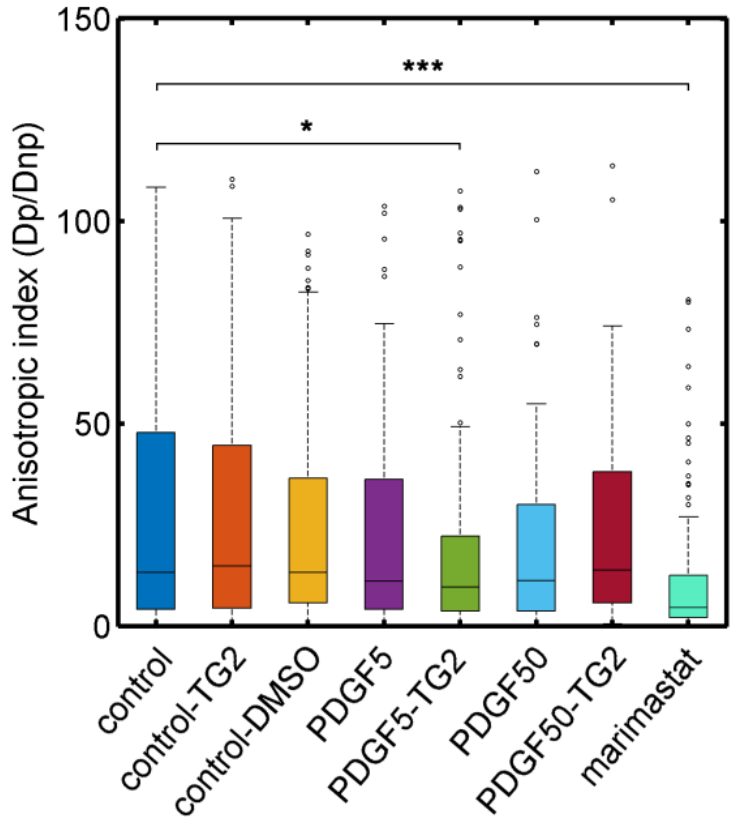

Fig.S2. Anisotropic index. ${ }^{* * *} p<0.001 ; * * p<0.01 ;{ }^{*} p<0.05$.

This is the post-print version of the following article: Movilla, N., Borau, C., Valero, C., \& García-Aznar, J. M. (2018). Degradation of extracellular matrix regulates osteoblast migration: A microfluidic-based study. Bone, 107, 10-17. doi: 10.1016/j.bone.2017.10.025, which has been published in final form here. 

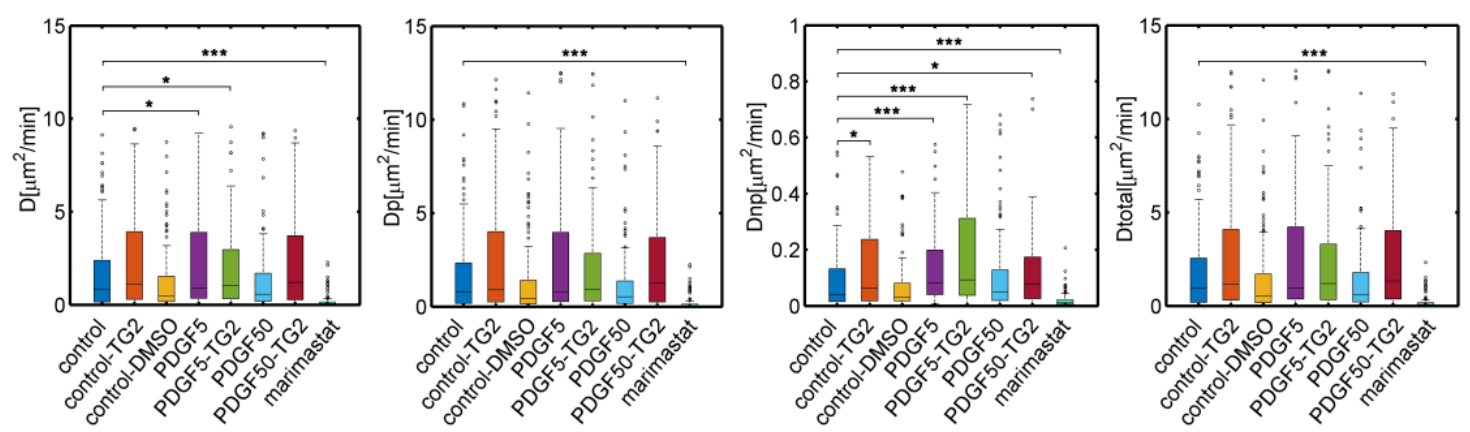

Fig.S3. Diffusion coefficient obtained by fitting a PRW model $(D)$ and an APRW model $\left(D_{\mathrm{p}}\right.$ and $\left.D_{\mathrm{np}}\right)$. $D_{\text {total }}$ is the sum of $D_{\mathrm{p}}$ and $D_{\mathrm{np}}$ and has the same meaning of $D$ in the PRW model. $* * * p<0.001 ; * * p<0.01 ;{ }^{*} p<0.05$.


Fig.S4. First row: persistence speeds obtained by fitting a PRW model $(S)$ and an APRW model $\left(S_{p}\right.$ and $\left.S_{n p}\right)$. Second row: persistence times obtained by fitting a PRW model $(P)$ and an APRW model $\left(P_{\mathrm{p}}\right.$ and $\left.P_{\mathrm{np}}\right) . * * \mathrm{p}<0.001 ; * * \mathrm{p}<0.01 ;{ }^{*} \mathrm{p}<0.05$.

This is the post-print version of the following article: Movilla, N., Borau, C., Valero, C., \& García-Aznar, J. M. (2018). Degradation of extracellular matrix regulates osteoblast migration: A microfluidic-based study. Bone, 107, 10-17. doi: 10.1016/j.bone.2017.10.025, which has been published in final form here. 


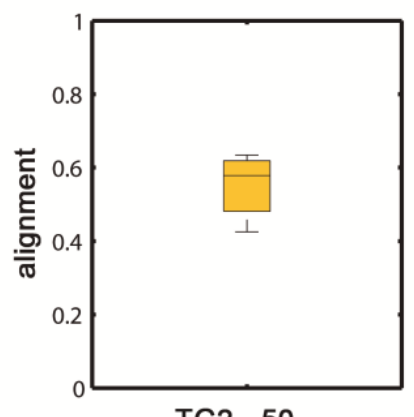

Fig. S5. Alignment index of $4 \mathrm{mg}$ with $50 \mu \mathrm{g} / \mathrm{ml} \mathrm{TG} 2$ collagen-based gel.
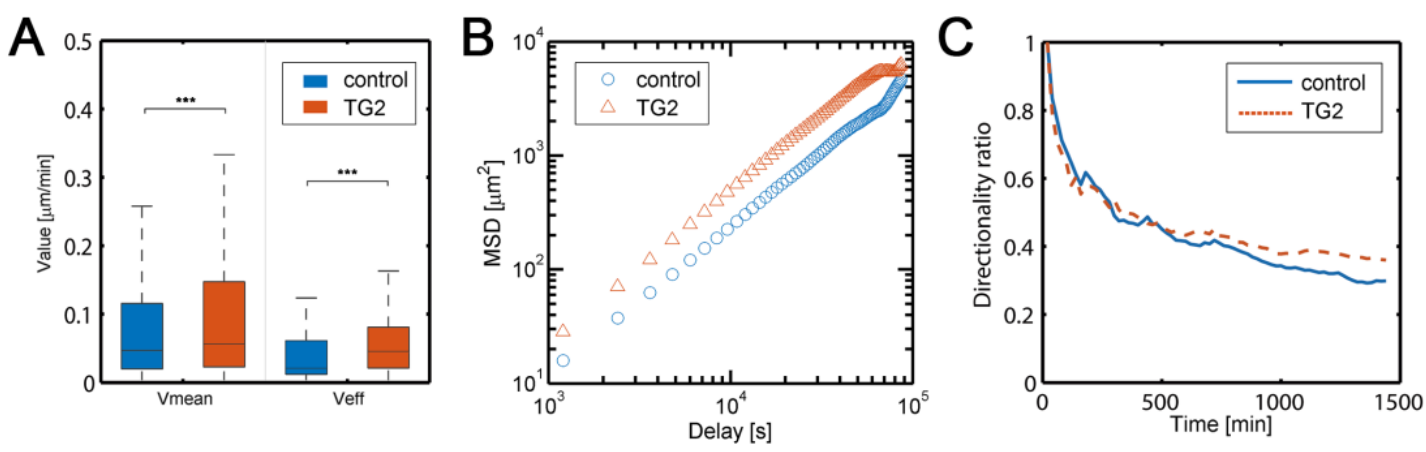

Fig. S6. (A) Mean and effective speeds of HOB cells, (B) mean squared displacement (MSD) of tracked trajectories and (C) directionality ratio of $4 \mathrm{mg} / \mathrm{ml}$ collagen with $50 \mu \mathrm{g} / \mathrm{ml} \mathrm{TG2}$ (orange curve) and without (blue curve) TG2. 50 $\mathrm{g} / \mathrm{ml} \mathrm{TG2}$ were used in two independent experiments with four technical replicas each. ${ }^{* *} p<0.001 ; * * p<0.01 ;{ }^{*} p<0.05$

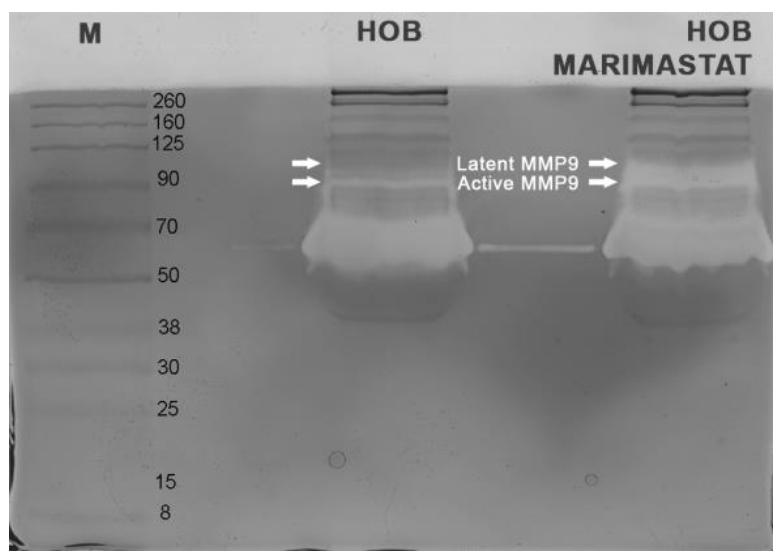

Fig.S7. Gelatin zymography of culture medium from HOB control and HOB marimastat treated cells. Chamaleon Duo was used as a marker (LI-COR). Samples were quantified, diluted with nondenaturing sample buffer and subjected to $10 \%$ SDS-PAGE containing $1 \mathrm{mg} / \mathrm{ml}$ of gelatin. Gelatinolytic reaction was induced overnight (16-18h). Latent MMP-9 was detected in culture

This is the post-print version of the following article: Movilla, N., Borau, C., Valero, C., \& García-Aznar, J. M. (2018). Degradation of extracellular matrix regulates osteoblast migration: A microfluidic-based study. Bone, 107, 10-17. doi: 10.1016/j.bone.2017.10.025, which has been published in final form here. 
medium of $\mathrm{HOB}-$ marimastat treated gels and not in the $\mathrm{HOB}$ control.

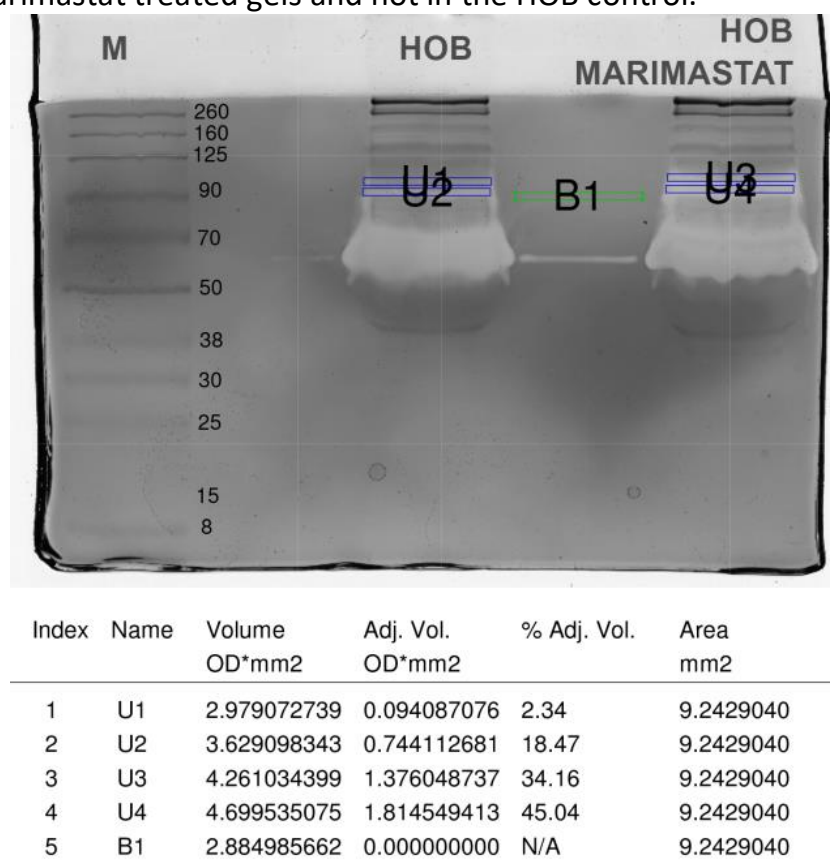

Fig.S8. Quantification of latent MMP-9 using densitometer GS-800 and Quantity One software (BioRad). Latent MM-P 9 is increased 15 -fold in HBO cells treated with marimastat compared to untreated cells.

This is the post-print version of the following article: Movilla, N., Borau, C., Valero, C., \& García-Aznar, J. M. (2018). Degradation of extracellular matrix regulates osteoblast migration: A microfluidic-based study. Bone, 107, 10-17. doi: 10.1016/j.bone.2017.10.025, which has been published in final form here. 